\section{Test of a safety culture model from a management perspective}

\author{
André Job ${ }^{1}$ \\ Isabel Silva ${ }^{1}$ \\ Tânia Moreira ${ }^{1}$ \\ ${ }^{1}$ University of Minho, School of Psychology, Braga, Portugal.
}

\begin{abstract}
Purpose - The importance of developing theoretical models and their empirical validation, capable of explaining safety performance within organizations, has been pointed out by the scientific community. Fernández-Muñiz, Montes-Peón, and Vazquez-Ordáz (2007) proposed a model that integrates dimensions considered as determinants of safety culture to explain safety performance, which was tested with Occupational Health and Safety technicians of Spanish companies. This study aims to verify if that theoretical model obtains empirical support in the Portuguese context, considering the supervisors' perspective. In addition, it also aims to contribute to the adaptation of the measurement instrument, which allowed for the empirical test of the model in the Portuguese context.
\end{abstract}

Design/methodology/approach - The study conducted is quantitative with a cross-sectional study design. In total, 174 supervisors at different levels of supervision, in different Portuguese companies from different activity sectors, participated in the study. Data were gathered through the Portuguese version of the instrument developed by the authors of the model (Fernández-Muñiz et al., 2007).

Findings - The results partially confirm the proposed model wherein supervisors play a determinant role in the development of safety culture and thus in the safety performance of organizations.

Originality/value - This study addresses one of the demands present in the literature, having empirically tested a model that aims to explain the safety performance of organizations, expanding its application to the management perspective and to a different national context. The results emphasize the role supervisors may play in the development of safer organizations.

Keywords - safety culture, occupational safety, safety performance, supervisors, theoretical model
Received on:

$7 / 12 / 2018$

Approved on:

7/03/2019

Responsible Editor:

Prof. Dr. Ilídio Tomás Lopes

Evaluation process:

Double Blind Review

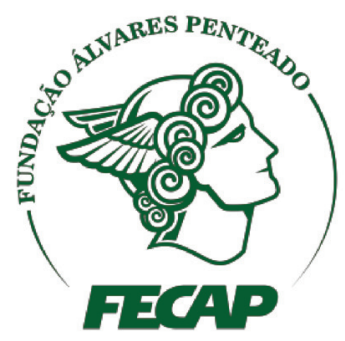

Revista Brasileira de Gestáo de Negócios 


\section{Introduction}

The concept of safety culture has received much attention from researchers and organizations (Choudhry, Fang, \& Mohamed, 2007). The concept can be perceived as a component of organizational culture that affects not only safety, but also workers' health (Ostrom, Wilhelmsen, \& Daplan, 1993). Although it seems to be an easily understood concept and there is a considerable amount of studies in this area, some authors (e.g. Cooper, 2000; Hopkins, 2006) have reported the lack of a consensual definition, which consequently leads to the existence of several conceptualizations (Choudhry et al., 2007; Fernández-Muñiz, Montes-Peón, \& VazquezOrdáz, 2007). For example, Guldenmund's (2000) review identified 18 different definitions, six for safety culture and 12 for safety climate.

According to Cooper (2000), it is essential to define this concept, as this will not only help to understand how safety culture should be analyzed in an organization, but will also help to define a measure that allows us to comprehend the degree to which an organization has a "good" safety culture (or not). It is also important to note that there is not only divergence among researchers concerning the definition of the concept, but also concerning its use, and there is an evident discussion in the scientific literature regarding the difference between "safety culture" and "safety climate" (Wiegmann, Zhang, Thaden, Sharma, \& Mitchell, 2002).

Some studies (e.g. Fernández-Muñiz et al., 2007; Halligan \& Zecevic, 2011; Stanton, Salmon, Jenkins, \& Walker, 2009) have conceived the concept of "safety culture" as a multidimensional construct, although there is a lack of consensus regarding all the dimensions and structures that constitute it. In this context, Guldenmund (2000) stated that it is very important for models to be developed since, as simple as these may be, they should be the starting point for any successful scientific advancement. Efforts to develop the theory have been scarce (Seo, Torabi, Blair, \& Ellis, 2004), and the present study aims to verify whether the theoretical model proposed by
Fernández-Muñiz et al. (2007) can be replicated (i.e. whether empirical support is obtained) in the Portuguese context considering the perspective of managers. This model, as will be seen below, is based on the concept of safety culture, and is therefore the focus of this paper.

\section{Literature review}

\section{I The concept of safety culture}

The concept of safety culture was first referenced in the literature after the Chernobyl disaster in 1986, when the investigating entity (International Nuclear Safety Advisory Group - INSAG) considered in its report "INSAG-1" (published in 1986 and revised in 1992) the lack of a "safety culture" as one of the factors that contributed to the occurrence of the accident (International Nuclear Safety Advisory Group [INSAG], 1992). Some years later, the same association provided a definition for the concept it would use in the post-disaster context, stating that safety culture is "that assembly of characteristics and attitudes in organizations and individuals which establishes that, as an overriding priority, nuclear plant safety issues receive the attention warranted by their significance" (INSAG, 1991).

Later, Ostrom et al. (1993) defined the concept as the intra-organizational beliefs and attitudes manifested through actions, policies, and procedures that affect safety performance. In turn, Locke and Latham (1990), as quoted in Cooper (2000, p. 115), postulate that this is "that observable degree of effort with which all organizational members direct their attention and actions towards improving safety on a daily basis." Richter and Koch (2004) describe it as the set of experiences, interpretations, and meanings regarding work and safety that are shared and learned by workers, which aim to guide their actions towards the prevention of risks and accidents. In turn, Reiman and Rollenhagen (2014, p. 7) state that "safety culture is more associated with safety-related values, assumptions, and norms," while Reicher and Schneider (1990) associate safety culture with terms such as "deep," "stable," "qualitative," and "trace," which is 
consistent with the studies of Cox and Flin (1998) and Schneider and Gunnarson (1991).

Given the fact that the present study is based on the model presented by FernándezMuñiz et al. (2007), it is crucial for the concept and definition they considered in their research to be adopted. Therefore, for the purpose of this study, the term safety culture will be used, which is defined as:

A set of values, perceptions, attitudes and patterns of behavior with regard to safety shared by members of the organization; as well as a set of policies, practices and procedures relating to the reduction of employees' exposure to occupational risks, implemented at every level of the organization, and reflecting a high level of concern and commitment to the prevention of accidents and illnesses (FernándezMuñiz et al., 2007, p. 628).

\subsection{Conceptual models regarding safety culture}

Of the existing models regarding the subject of safety culture, Cooper's (2001) stands out as perhaps the most recognized in the area. This model adapts Bandura's reciprocal determinism model to safety, conceiving the concept as a combination of dynamic relationships between workers' attitudes, their safety behavior, and the presence of the organization's safety management system (SMS). However, Porkka (2016) stated that such a model proves to be insufficient with regards to SMS, which corroborates the idea of Fernández-Muñiz et al. (2007), who argued that the existing literature (e.g. Donald \& Young, 1996; Watcher \& Yorio, 2014) has focused more on the analysis of workers' perceptions, attitudes, and behaviors, placing less emphasis on the situational characteristics of the SMS, although authors such as Hale, Heming, Carthey, and Kirwan (1997) have alluded to their huge importance.

Based on an extensive literature review, Fernández-Muñiz et al. (2007) proposed a conceptual model, in which they not only identified three key indicators of this concept (managers' commitment to safety, employees' involvement, and the policies and procedures that form the SMS), but also, according to Frazier, Ludwig, Whitaker, and Roberts (2013), expanded scientific knowledge in relation to SMS, suggesting the dimensions that constitute it. The first factor (managers' commitment) can be operationalized as:

The extent to which the firm's managers are committed to their workers' safety. This commitment can be manifested in positive attitudes toward the activities relating to safety management and in the behaviors visible to the workers (Fernández-Muñiz et al., 2007, p. 631).

According to the same authors, a considerable number of studies show that managers' commitment to safety is a determining condition of workers' attitudes and behaviors regarding risk. For example, if a manager engages in safety-enhancing activities, revealing concern about safety-related issues, he/she more easily influences workers' behaviors in a positive way, who will, for example, display greater respect for safety regulations.

The second factor concerns employees' involvement in improving working conditions and their degree of compliance to safety procedures (Fernández-Muñiz et al., 2007). The authors of the model justify the inclusion of both factors - managers' commitment and employees' involvement - stating that these have been identified and replicated in several studies (e.g. Cox \& Cheyne, 2000; Hofmann \& Stetzer, 1996).

Lastly, the third factor (SMS) is defined as "the set of integrated mechanisms in the organization, comprising policies, strategies, and procedures" (Fernández-Muñiz et al., 2007, p. 630). Petersen (2000) stated that this factor will have a direct effect on reducing the organization's accident rates. Consequently, if the goal is to understand which dimensions have an impact on safety performance, it is crucial to take this variable into account. In the model presented by Fernández-Muñiz et al. (2007), the SMS integrates six key dimensions, two of which are 
subdivided into two others. Specifically, the model considers the following dimensions: i) Safety policy, regarding whether there is a written statement that reflects the organization's commitment to safety as well as its integration with the other policies of the organization; ii) Incentives, concerning whether the organization encourages workers to participate in activities related to their safety; iii) Training, regarding whether training plans in the organization are meant to develop workers' safety skills; iv) Communication, related to informing workers about the possible risks of their work environment while providing solutions to combat them; v) Planning, which is divided into two constructs: preventive planning (the existence of procedures for risk assessment and safety measures to prevent risks) and emergency planning (whether or not there are emergency plans in case an accident occurs); and vi) Control, which is also subdivided into two constructs: internal controls (the existence of practices or mechanisms that allow us to understand if the objectives have been achieved as well as the degree of commitment to the work norms and procedures) and benchmarking techniques (the comparisons that the organization makes with competing organizations regarding safety actions).

Finally, another dimension present in the model of Fernández-Muñiz et al. (2007) was described as safety performance, which intends to measure the direct consequences of the safety culture on safety. In order to evaluate safety performance, the authors considered the following predictor variables: absenteeism or lost time, employees' motivation, material damage, and the number of personal injuries. In this context, as stated by Glendon and Litherland (2001), it is important to note that there is no adequate and valid measure for the safety performance variable and that the traditional measure (i.e. the number of accidents or amount of damage in a given time period) is problematic, in that as well as ignoring risk exposure, its accuracy is doubtful.

\subsection{Objectives}

The model proposed by Fernández-Muñiz et al. (2007) was validated by them based on the perception of safety technicians from Spanish organizations. In this context, it is important to note that, as stated by Reader, Noort, Shorrock, and Kirwan (2015, p. 770), "safety management transcends national boundaries, and is of international concern. This means the conceptual models used to measure and understand safety culture must be valid for different national contexts.”

Thus, the main goal of this study is to understand if the model is replicated in the perceptions of managers in the Portuguese context, as this will enable an increase in its reliability. The hypotheses of the original study were adapted to the perceptions of managers, which are considered as specific objectives of this study (Figure 1):

$\mathbf{H}_{1}$ - Managers' commitment has a positive impact on employees' involvement in safety activities.

$\mathbf{H}_{2}$ - A high degree of development of the safety management system positively influences employees' involvement in safety activities.

$\mathbf{H}_{3}$ - Manager's commitment positively influences safety management system development.

$\mathbf{H}_{4}$ - Employees' participation in safetyrelated activities positively influences the safety performance of the organization.

$\mathbf{H}_{5}$ - A high degree of development of the safety management system has a positive impact on safety performance.

Additionally, it was also the objective of this study to contribute to the adaptation and validation of the measurement instrument developed by Fernández-Muñiz et al. (2007) as part of the empirical test of their safety culture model. 


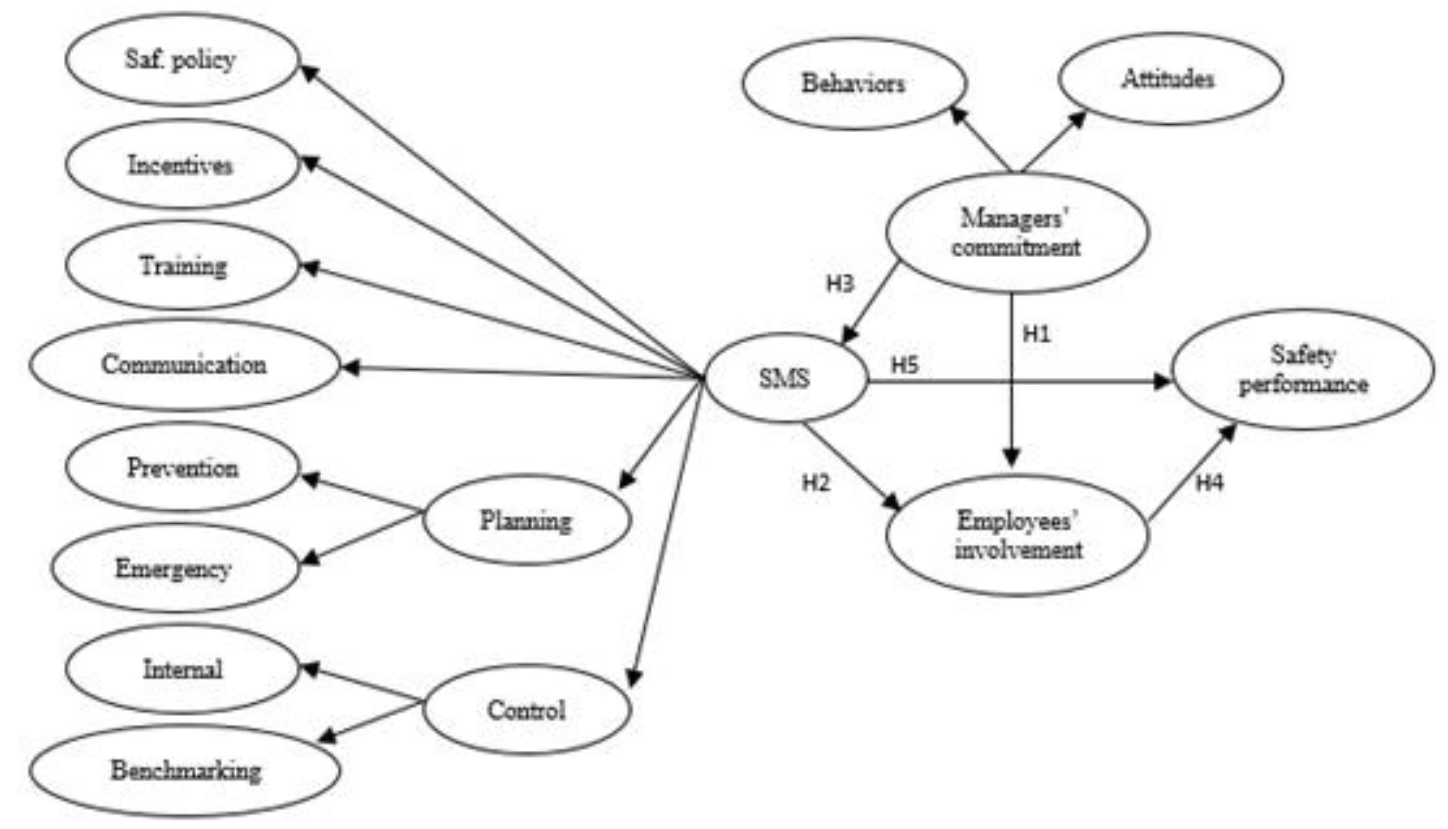

Figure 1. Model proposed by Fernández-Muñiz et al. (2007)

Source: Retrieved from "Safety culture: Analysis of the causal relationships between its key dimensions" of B. Fernández-Muñiz, J. Montes-Peón, and C. Vázquez-Ordás, 2007, Journal of Safety Research, 38(6), p. 635.

\section{Methodology}

\section{I Procedures}

The first step consisted of presenting the project of the present study to the Ethics Subcommittee on Social and Human Sciences of the University of Minho, which gave a positive opinion (SECSH 058/2016). Afterwards, permission from the authors was requested for the validation and use of the measurement instrument. Once all the authorizations were obtained, the instrument was translated into Portuguese and subsequently validated through a back-translation by a bilingual individual (English-Portuguese). In a subsequent phase, the translation obtained from the previous process was validated by a work safety and health technician with several years' experience in this field, and a four-subject pretest was also performed. In this pretest, no questions were raised regarding comprehension of any of the items.

In the sample definition, we sought to follow the indications of Kline (2016), who stated that it is not possible to define a minimum number of participants to perform structural equations that work for all studies, as this number will always vary depending on the complexity of the model; but 200 participants is often considered acceptable. In this regard, Barrett (2007) also raised reservations about a sample of less than 200 participants. In order to maximize the sample size, the data collection phase was initially executed online and later on paper. Regarding the first method, the link to the questionnaire was disseminated to various organizations via email. This was accessed by 222 potential participants, of which 42 answered the questionnaire in full, resulting in a response rate of $18.92 \%$. As the response rate through the online method proved to be insufficient, the decision was made to apply the questionnaire in paper format through direct and personal contact with various organizations in Braga, a region in the north of Portugal. Thus, 220 questionnaires were distributed, of which 132 were returned correctly completed, resulting in a response rate of approximately $60 \%$. The data collection period started in February 2017 and lasted about five months. 


\subsection{Sample}

A total of 174 managers from different hierarchical levels and organizations participated

Table 1

Socio-demographic characterization of the sample $(N=174)$

\begin{tabular}{|c|c|c|}
\hline Variables & & n (\%) \\
\hline \multirow{2}{*}{ Gender } & Female & $64(36.8)$ \\
\hline & Male & $109(62.6)$ \\
\hline \multirow{3}{*}{ Age Range } & Up to 25 years old & $3(1.7)$ \\
\hline & Between 26 and 40 years old & $82(47.1)$ \\
\hline & 41 years old and above & $87(50.0)$ \\
\hline \multirow{5}{*}{ Educational Level } & $1^{\text {st }}$ Cycle of Basic Education ( $4^{\text {th }}$ grade) & $2(1.1)$ \\
\hline & $2^{\text {nd }}$ Cycle of Basic Education ( $6^{\text {th }}$ grade) & $3(1.7)$ \\
\hline & $3^{\text {rd }}$ Cycle of Basic Education ( $9^{\text {th }}$ grade) & $11(6.3)$ \\
\hline & Secondary Education or equivalent & $48(27.6)$ \\
\hline & Higher Education & $110(63.2)$ \\
\hline \multirow{5}{*}{ Type of Managers } & Administrator & $39(22.4)$ \\
\hline & Director & $41(23.6)$ \\
\hline & Middle manager & $51(29.3)$ \\
\hline & Direct manager & $22(14.9)$ \\
\hline & Other & $9(5.2)$ \\
\hline \multirow{4}{*}{ Sector } & Industry & $86(49.4)$ \\
\hline & Construction & $14(8.0)$ \\
\hline & Services & $64(36.8)$ \\
\hline & Other & $8(4.6)$ \\
\hline \multirow{4}{*}{ Company Size } & Micro (< 10 workers) & $30(17.2)$ \\
\hline & Small (10-50 workers) & $50(28.7)$ \\
\hline & Medium (51-250 workers) & $42(24.1)$ \\
\hline & Large (> 250 workers) & $52(29.9)$ \\
\hline
\end{tabular}

Note. The values in the table may, in some cases, not equal the sample total due to missing values in some variables. in the study, with an average length of stay of 9.06 years $(S D=7.96)$ in the organization (Table 1$)$. 


\subsection{Instruments}

The research protocol used for the data collection contained two parts. The first was a sample characterization questionnaire, and the second was a questionnaire regarding the measures that are part of the model to be studied. Specifically, the sample characterization questionnaire collected information regarding the participants' socio-demographic data (e.g. gender, age), type of management, and length of stay in the organization, and the organization's sector of activity and size (number of workers). This questionnaire was created within the scope of this study, consisting of eight questions: seven closed response (with two or more answer options) and one open response (length of stay in the organization) (Appendix A).

With regards to the questionnaire concerning the variables of the conceptual model proposed by Fernández-Muñiz et al. (2007), all the questions that composed it were answered on a five-point Likert scale (1 - "Strongly Disagree" to 5 - "Totally Agree"), aiming to collect data on all the dimensions mentioned above. The original version has good validity indices. The lowest Cronbach's alpha of its component dimensions was .71 (belonging to Safety Policy), while the highest Cronbach's alpha of its component dimensions was .85 (belonging to Internal Controls). In total, the questionnaire consists of 57 items divided into 12 asymmetrically distributed dimensions, ranging between two items for the Benchmarking dimension and nine items for the Training dimension (Appendix B).

\subsection{Statistical analysis of the data}

The statistical analysis of the data used version 21 of the Statistical Package for the Social Sciences (SPSS) program as well as Analysis of Moment Structures (AMOS). The analysis began with an exploratory data analysis. Afterwards, confirmatory factor analysis was conducted, followed by an analysis of the measurement component of each dimension, and subsequently of the structural model in order to obtain statistical information about the congruence between the specified model and the reality of the data.

\section{Presentation and Analysis of Results}

\section{I Exploratory data analysis}

The exploratory data analysis revealed the presence of missing values $(0.49 \%)$, which motivated an analysis of their pattern, and for this the Little test was performed. The results of this test $\left(\chi^{2}=638.621 ; \mathrm{df}=753 ; \mathrm{p}>.05\right)$ lead to the acceptance of the null hypothesis, meaning that the missing data are completely random, therefore enabling the use of maximum-likelihood estimation methods.

Taking into account the fact that the sample collected is not representative of the universe (the universe being, in this case, managers working in organizations in Portugal), it was decided to use the expectation-maximization algorithm in order to replace these values with an estimate instead of excluding cases. According to several authors (e.g. Little \& Rubin, 1989; Schaffer, 1997), all procedures for estimating missing values may present biases, however when compared with other methods, maximumlikelihood estimation methods (which include the expectation-maximization algorithm) are the ones with the least biased results.

\subsection{Confirmatory data analysis}

The overall adjustment quality of the models (measurement and structural) was evaluated according to the same adjustment indices used by Fernández-Muñiz et al. (2007): Chi-Square to Degrees of Freedom Ratio $\left(\chi^{2} / g l\right)$, Goodness-of-Fit Index (GFI) and Adjusted Goodness-of-Fit Index (AGFI), Comparative Fit Index (CFI), Tucker-Lewis Index (TLI), Incremental Fit Index (IFI), and Root Mean Square Error of Approximation (RMSEA), P[RMSEA $\leq$ 0.05].

Initially, an analysis was carried out of the measurement components of the proposed model. All dimensions included in the model were tested separately, and the validity of the measurement was analyzed using Cronbach's alpha, as well as the convergent validity, multicollinearity, and the assumptions of normality. 
The SMS measure presented some problems in terms of convergent validity and multicollinearity, whereas all other indicators (Cronbach's alpha, asymmetry, and kurtosis) had acceptable values (a $>$.70; $|\mathrm{SK}|<3$; $|\mathrm{Ku}|<7$ ) (Maroco, 2010). In this dimension, two items ("Train7" and "Train8") related to the latent variable Training were not considered in the following analyses since they had a factor weight lower than the .50 value recommended by Pestana and Gageiro (2005).

Convergent validity was assessed using the $\mathrm{t}$-values and $\mathrm{R}^{2}$ indicators. In the first case, $\mathrm{t}>$ 1.96 is considered acceptable, and in the second case, the Koufteros (1999) criterion was used, which suggests the elimination of items with a correlation below . 50. Thus, by eliminating items that did not meet the second criterion (Table 2 ), there may be a slight improvement in the adjustment indices of the SMS measure (Figure 2). Regarding multicollinearity, some problems were also identified as the second-order factors (prevention and control) showed a covariance greater than .80 (Field, 2009). These were then eliminated in a further analysis, which resulted in a change in the measurement component of the Safety Management System from the original study.

Table 2

Measurement component analysis: Safety Management System (SMS)

\begin{tabular}{|c|c|c|c|c|c|c|c|}
\hline Dimension & Variables & $\begin{array}{l}\text { Cronbach's } \\
\text { alpha }\end{array}$ & $\begin{array}{c}\text { Factorial weight } \\
\text { (non-standardized) }\end{array}$ & $\begin{array}{l}\text { Factorial weight } \\
\text { (standardized) }\end{array}$ & Errors & t-values & $\mathbf{R}^{2}$ \\
\hline \multirow{4}{*}{ Safety Policy } & Pol1 & \multirow{4}{*}{.82} & .645 & .700 & .069 & 9.326 & $.491^{\mathrm{b}}$ \\
\hline & Pol2 & & .879 & .718 & .092 & 9.557 & .513 \\
\hline & Pol3 & & $-^{a}$ & .809 & $-a^{a}$ & $\mathrm{a}^{\mathrm{a}}$ & .651 \\
\hline & Pol4 & & .741 & .727 & .076 & 9.756 & .532 \\
\hline \multirow{5}{*}{ Incentives } & Incent1 & \multirow{5}{*}{.83} & .945 & .598 & .130 & 7.399 & $.364^{\mathrm{b}}$ \\
\hline & Incent2 & & .791 & .720 & .091 & 8.896 & .529 \\
\hline & Incent3 & & .755 & .632 & .099 & 7.756 & $.400^{\mathrm{b}}$ \\
\hline & Incent 4 & & .932 & .695 & .111 & 8.519 & $.484^{\mathrm{b}}$ \\
\hline & Incent5 & & $-^{\mathrm{a}}$ & .734 & $-^{a}$ & $-a^{a}$ & .525 \\
\hline \multirow{7}{*}{ Training } & Train 1 & \multirow{7}{*}{.86} & .733 & .657 & .089 & 9.513 & $.484^{\mathrm{b}}$ \\
\hline & Train2 & & .977 & .780 & .098 & 11.034 & .621 \\
\hline & Train3 & & .982 & .815 & .079 & 13.156 & .621 \\
\hline & Train 4 & & $-^{a}$ & .846 & $-a^{a}$ & $-a^{a}$ & .602 \\
\hline & Train5 & & .915 & .746 & .067 & 13.660 & $.490^{\mathrm{b}}$ \\
\hline & Train6 & & .930 & .691 & .108 & 9.223 & $.459^{\mathrm{b}}$ \\
\hline & Train9 & & .827 & .711 & .092 & 10.333 & .557 \\
\hline \multirow{4}{*}{ Communication } & Commun 1 & \multirow{4}{*}{.78} & .838 & .732 & .084 & 9.766 & .523 \\
\hline & Commun2 & & .493 & .521 & .073 & 6.915 & $.283^{\mathrm{b}}$ \\
\hline & Commun3 & & .858 & .697 & .091 & 9.413 & $.491^{\mathrm{b}}$ \\
\hline & Commun4 & & $-^{a}$ & .781 & $-^{a}$ & $-^{a}$ & .614 \\
\hline
\end{tabular}




\begin{tabular}{|c|c|c|c|c|c|c|c|}
\hline Dimension & Variables & $\begin{array}{l}\text { Cronbach's } \\
\text { alpha }\end{array}$ & $\begin{array}{c}\text { Factorial weight } \\
\text { (non-standardized) }\end{array}$ & $\begin{array}{l}\text { Factorial weight } \\
\text { (standardized) }\end{array}$ & Errors & t-values & $\mathbf{R}^{2}$ \\
\hline \multirow{7}{*}{$\begin{array}{l}\text { Preventive } \\
\text { planning }\end{array}$} & Prevent1 & \multirow{7}{*}{.93} & .844 & .780 & .074 & 12.033 & .621 \\
\hline & Prevent2 & & $-^{a}$ & .852 & $a^{-a}$ & $a^{-a}$ & .673 \\
\hline & Prevent3 & & .985 & .881 & .054 & 18.423 & .733 \\
\hline & Prevent 4 & & .878 & .814 & .072 & 12.661 & .666 \\
\hline & Prevent 5 & & .768 & .798 & .065 & 12.554 & .659 \\
\hline & Prevent6 & & .891 & .764 & .081 & 11.214 & .563 \\
\hline & Prevent7 & & .847 & .797 & .072 & 12.087 & .626 \\
\hline \multirow{4}{*}{$\begin{array}{l}\text { Emergency } \\
\text { planning }\end{array}$} & Emerg1 & \multirow{4}{*}{.90} & .877 & .828 & .063 & 13.912 & .684 \\
\hline & Emerg2 & & $-a^{a}$ & .859 & $-^{\mathrm{a}}$ & $-^{\mathrm{a}}$ & .736 \\
\hline & Emerg3 & & .983 & .942 & .056 & 17.474 & .890 \\
\hline & Emerg4 & & .938 & .737 & .081 & 11.531 & .541 \\
\hline \multirow{5}{*}{ Internal Control } & Intern 1 & \multirow{5}{*}{.91} & .907 & .863 & .064 & 14.870 & .770 \\
\hline & Intern2 & & .957 & .882 & .065 & 15.230 & .793 \\
\hline & Intern3 & & .937 & .793 & .064 & 14.372 & .574 \\
\hline & Intern4 & & $-^{a}$ & .872 & $-a^{a}$ & $-^{a}$ & .717 \\
\hline & Intern5 & & .608 & .635 & .068 & 9.071 & $.394^{\mathrm{b}}$ \\
\hline \multirow{2}{*}{ Benchmarking } & Bench1 & \multirow{2}{*}{.83} & .911 & .788 & .100 & 9.557 & .614 \\
\hline & Bench2 & & $-a$ & .895 & $-a^{a}$ & $-^{a}$ & .810 \\
\hline
\end{tabular}

Note. Adjustment indices of original solution: $\chi^{2}(641)=1445.427, \mathrm{p}=.000, \chi^{2} / \mathrm{gl}=2.255 ; \mathrm{RMSEA}=.085 ; \mathrm{CFI}=.844 ; \mathrm{TLI}=.829 ; \mathrm{IFI}=$ $.846 ; \mathrm{GFI}=.695 ; \mathrm{AGFI}=.648$.

a Parameter set to 1.0 in original solution

${ }^{\mathrm{b}}$ Items not considered in subsequent reviews

To re-specify the model, the modification indices (MI) were used (above 11; p <.001), and some covariance was identified between item errors, namely between the items "Train3" ("Training actions are continuous and periodic, and are integrated in a formally established training plan") and "Train4" ("Training plans are elaborated taking into account the firm's particular characteristics"), between the items "Prevent1" ("The firm has systems to identify risks in all job positions") and "Prevent5" ("Standards of action or work procedures are elaborated based on risk evaluations"), and lastly between the items "Intern 1" ("Periodic checks are conducted regarding the execution of prevention plans and the level of compliance with regulations") and "Intern3" ("Procedures are in place [reports, periodic statistics] to check the achievement of objectives allocated to managers").

All the changes to the measurement component in the SMS dimension resulted in the model shown in Figure 2. The adjustment indices, despite some improvements after the modifications, still do not reach acceptable cut-off points, and although the RMSEA indicator tends to be overestimated for small samples with few degrees of freedom, it still shows a value above .08. The CFI, TLI, IFI, GFI, and AGFI indicators have values below .90 , yet it is important to note that the CFI, TLI, and IFI have values very close to this cutoff point. On the other hand, the $\chi^{2} / \mathrm{gl}$ index is considered acceptable. 


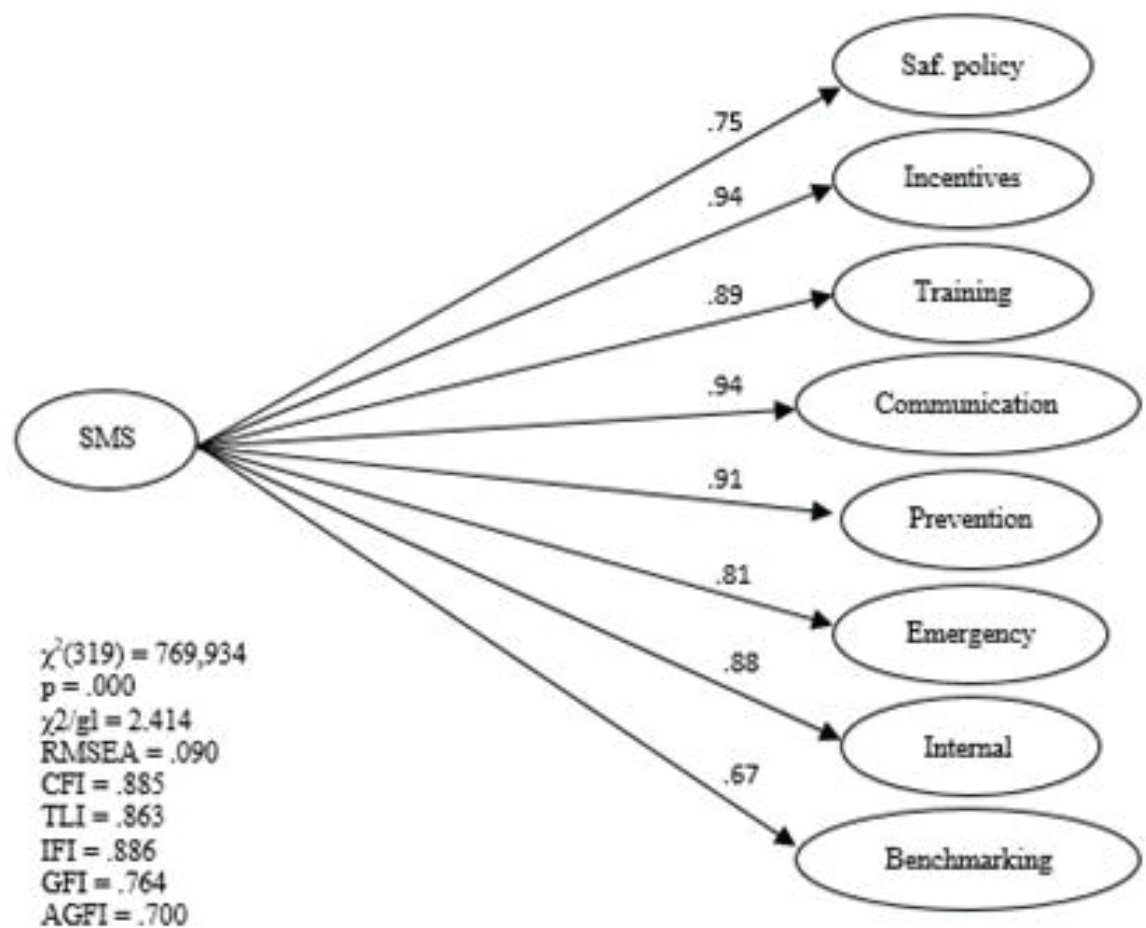

Figure 2. Final diagram of the Security Management System (SMS) measurement component

Regarding the measurement component of managers' commitment, both variables (attitudes and behavior) presented Cronbach's alphas higher than .70 and the adjustment indices were considered acceptable (Table 3).

Table 3

Measurement Component Analysis: Managers' commitment

\begin{tabular}{|c|c|c|c|c|c|c|c|}
\hline Dimension & Variables & $\begin{array}{l}\text { Cronbach's } \\
\text { alpha }\end{array}$ & $\begin{array}{c}\text { Factorial } \\
\text { weight (non- } \\
\text { standardized) }\end{array}$ & $\begin{array}{l}\text { Factorial weight } \\
\text { (standardized) }\end{array}$ & Errors & t-values & $\mathrm{R}^{2}$ \\
\hline \multirow{4}{*}{ Managers' attitudes } & Attitud1 & \multirow{4}{*}{.93} & .928 & .839 & .059 & 15.645 & .705 \\
\hline & Attitud2 & & .956 & .879 & .055 & 17.308 & .773 \\
\hline & Attitud3 & & .954 & .858 & .058 & 16.483 & .737 \\
\hline & Attitud4 & & $-^{\mathrm{a}}$ & .910 & $--^{a}$ & $--^{a}$ & .828 \\
\hline \multirow{5}{*}{ Managers' behaviors } & Behav1 & \multirow{5}{*}{.88} & .836 & .829 & .096 & 8.723 & .687 \\
\hline & Behav2 & & .979 & .887 & .088 & 11.079 & .787 \\
\hline & Behav3 & & .817 & .716 & .090 & 9.045 & .513 \\
\hline & Behav4 & & .855 & .780 & .087 & 9.834 & .609 \\
\hline & Behav5 & & $-^{\mathrm{a}}$ & .720 & $-{ }^{a}$ & $-^{\mathrm{a}}$ & .518 \\
\hline
\end{tabular}

Note. Adjustment indices of original solution: $\chi^{2}(25)=48.256 \mathrm{p}=.003, \chi^{2} / \mathrm{gl}=1,930 ;$ RMSEA $=.073 ;$ CFI $=.980 ;$ TLI $=.971 ; \mathrm{IFI}=.980$; $\mathrm{GFI}=.943$; AGFI $=.898$.

${ }^{\text {a }}$ Parameter set to 1.0 in original solution

${ }^{\mathrm{b}}$ Items not considered in subsequent reviews 
The measurement component concerning employees' involvement presented a Cronbach's alpha of .82, besides having good levels of adjustment and keeping all items on the scale (Table 4).

Table 4

Measure Component Analysis: Employees' involvement

\begin{tabular}{|c|c|c|c|c|c|c|c|}
\hline Dimension & Variables & $\begin{array}{l}\text { Cronbach's } \\
\text { alpha }\end{array}$ & $\begin{array}{l}\text { Factorial weight } \\
\text { (non-standardized) }\end{array}$ & $\begin{array}{l}\text { Factorial weight } \\
\text { (standardized) }\end{array}$ & Errors & t-values & $\mathbf{R}^{2}$ \\
\hline \multirow{4}{*}{$\begin{array}{l}\text { Employees' } \\
\text { involvement }\end{array}$} & Involv1 & \multirow{4}{*}{.82} & $-a^{a}$ & .777 & $-a^{a}$ & $-{ }^{a}$ & .770 \\
\hline & Involv2 & & .912 & .795 & .086 & 10.541 & .632 \\
\hline & Involv3 & & .609 & .612 & .075 & 8.086 & .503 \\
\hline & Involv4 & & .832 & .635 & .100 & 8.423 & .501 \\
\hline
\end{tabular}

Note. Adjustment indices of original solution: $\chi^{2}(2)=4.052 \mathrm{p}=.132, \chi^{2} / \mathrm{gl}=2.026$; RMSEA = .077; CFI = .992; $\mathrm{TLI}=.975 ; \mathrm{GFI}=.988 ; \mathrm{IFI}=.992 ; \mathrm{AGFI}=.942$;

a Parameter set to 1.0 in original solution

${ }^{\mathrm{b}}$ Items not considered in subsequent reviews

Finally, the measurement component referring to safety performance also maintained all items, showing a Cronbach's alpha of .80 and presenting adjustment levels considered acceptable (Table 5).

Table 5

Measurement Component Analysis: Safety performance

\begin{tabular}{|c|c|c|c|c|c|c|c|}
\hline Dimension & Variables & $\begin{array}{c}\text { Cronbach's } \\
\text { alpha }\end{array}$ & $\begin{array}{c}\text { Factorial weight } \\
\text { (non-standardized) }\end{array}$ & $\begin{array}{c}\text { Factorial weight } \\
\text { (standardized) }\end{array}$ & Errors & t-values & $\mathbf{R}^{2}$ \\
\hline \multirow{4}{*}{$\begin{array}{l}\text { Safety } \\
\text { performance }\end{array}$} & Safety 1 & \multirow{4}{*}{.80} & .858 & .708 & .104 & 8.256 & .502 \\
\hline & Safety2 & & $-^{a}$ & .779 & $--^{a}$ & $--^{a}$ & .606 \\
\hline & Safety3 & & .878 & .711 & .106 & 8.277 & .505 \\
\hline & Safety 4 & & .966 & .664 & .124 & 7.818 & .541 \\
\hline
\end{tabular}

Note. Adjustment indices of original solution: $\chi^{2}(2)=4.075 \mathrm{p}=.130, \chi^{2} / \mathrm{gl}=2.038$; RMSEA $=.077$; CFI $=.990$; TLI $=$ $.971 ; \mathrm{GFI}=.988 ; \mathrm{IFI}=.990 ; \mathrm{AGFI}=.939$;

a Parameter set to 1.0 in original solution

${ }^{\mathrm{b}}$ Items not considered in subsequent reviews

The results of the structural analysis of the model indicate a relatively poor fit, although the $\chi^{2} / \mathrm{gl}$ (2.082) and SRMR (.071) indices have acceptable values. The RMSEA (.079) has a value very close to the cutoff point (.08) translating a poor adjustment of the model; the remaining indices have values below the acceptable value (.90) (Figure 3). 


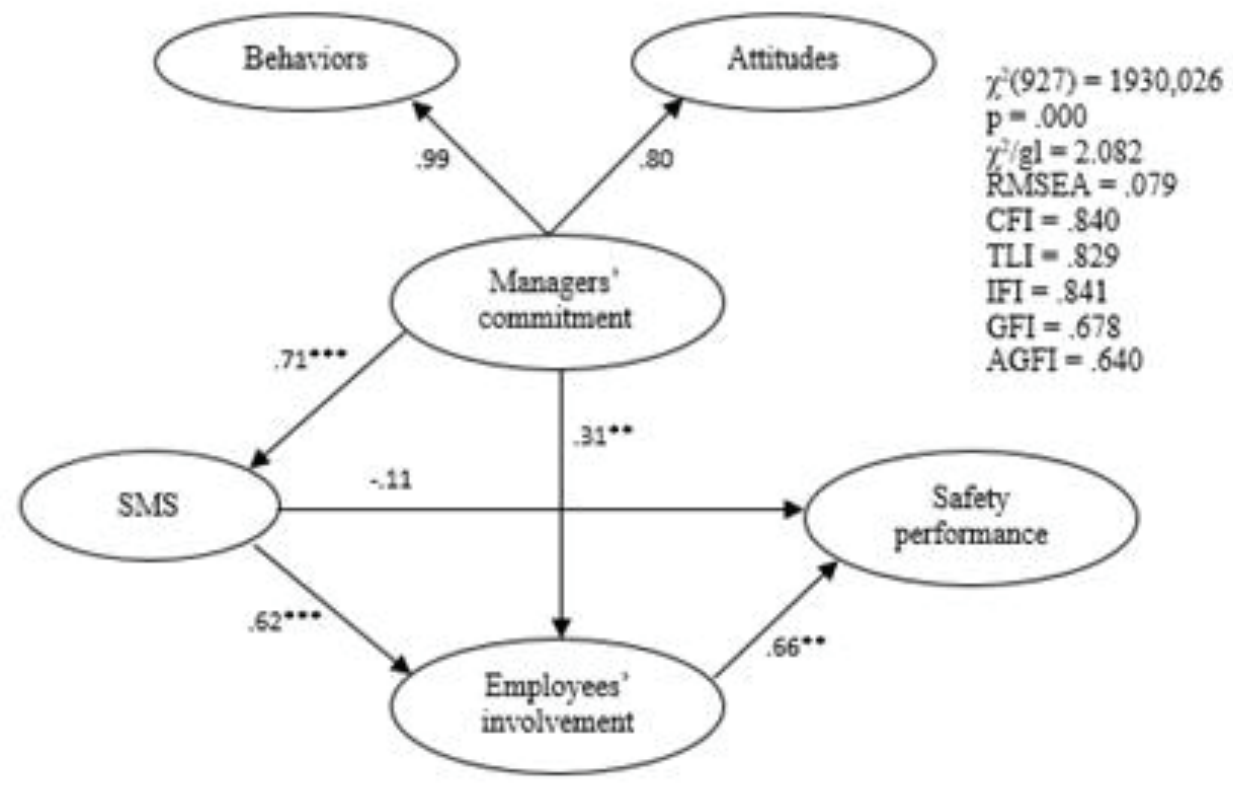

Note. ${ }^{* *} p<.01{ }^{* * *} p<.001$

Figure 3. Proposed model test results (standard values)

Regarding the direct structural relationships, four statistically significant relationships were found in the model $(\mathrm{p}<.05)$. Managers' commitment has a positive impact on employees' involvement $(=.31, \mathrm{p}<.01)$, confirming the first hypothesis presented (H1). Regarding the SMS component, it has a positive impact on employees' involvement $(=.62$, $\mathrm{p}<.001$ ), thus confirming the second hypothesis (H2). In addition, managers' commitment also has a positive impact on SMS $(=.71, \mathrm{p}<.001)$, which corroborates the third hypothesis of the study (H3). In turn, employees' involvement has a positive impact on safety performance $(=.66$, $\mathrm{p}<.01)$, corroborating the fourth hypothesis (H4). Finally, contrary to expectations, SMS does not have a direct impact on safety performance ( = -.11, p = .545), leading to the rejection of the fifth hypothesis (H5).

\section{Discussion of results}

In the present study, the model proposed by Fernández-Muñiz et al. (2007) was tested, thus contributing to the adaptation of its measurement instrument to the Portuguese context. The abovementioned model sets a precedent for the results obtained, as the data were collected in a different country and, most importantly, with a different target audience, which may be one of the explanations for the model's poor adjustment to the data. Regarding the first hypothesis established in the model, our results point to the fact that managers, through their attitudes and behaviors, positively influence employees' involvement in safety activities, thus being one of the focal points to work on to improve the safety performance of a given organization. This result corroborates the findings of the study of Fernández-Muñiz et al. (2007) and may also indicate the truth of the "contrary" idea advocated by Hofmann, Jacobs, and Landy (1995), i.e. a supervisor who never mentions safety-related matters may convey the idea that he/she gives higher priority to production than to workers' own safety.

As for the second hypothesis (H2), the results show that employees' involvement in safety activities is not only influenced by 
managers' commitment, but also by the safety management system. Authors such as Donald and Young (1996), Michael, Evans, Jansen, and Haight (2005), and Watcher and Yorio (2014) have also advocated the influence of employees' involvement in the development of the safety management system. This influence is based on the assumption that greater employee involvement (i.e. active participation through suggestions for improvement) will lead to further and more appropriate development of the safety management system, as it is the workers who experience "first-hand" safety issues in the performance of their duties. Yet, in the model presented by Fernández-Muñiz et al. (2007), the opposite impact was tested and confirmed (i.e. the influence of the SMS on employees' involvement). Our study also corroborates this impact, which may indicate that there is a reciprocal relationship between these variables, forcing us to look at the model from a systemic perspective and not independently. As mentioned earlier, the SMS corresponds to the set of policies, strategies, and procedures of a given organization, which thus leads us to a level of organizational analysis that consequently encompasses the administration and management frameworks. Therefore, it should not only be taken into account whether or not workers actively participate in safety issues and the development of the safety management system, but also the way in which this participation is reinforced (or not) by that system, since it is not independent of the organization's management practices and styles.

The third hypothesis (H3 - Managers' commitment positively influences safety management system development) was also confirmed, which is in line with the conclusions reached by Fernández-Muñiz et al. (2007). In this sense, the importance of managers' commitment is reinforced, since this not only influences employees' involvement directly (H1), but also indirectly by influencing the security management system by supporting or assisting in the practical implementation of measures of the safety system or even in its development. This may also be evidence that the model should be interpreted as a whole, being more than the "simple sum of all its parts."

Michael et al., (2005) stated that if workers perceive high manager commitment regarding safety issues, they will adopt safer behaviors and are less likely to be at risk since this commitment is supported by proper implementation of the safety management system, and they will adopt safer behaviors and are less likely to be at risk. Along the same line of thought, Watcher and Yorio (2014) argued that the greater the involvement/participation of workers in the development and participation of processes, procedures, and programs related to the safety issues that affect them, the greater their identification with them and their engagement with the subject matter. All these statements confirm the fourth hypothesis (H4), which stipulates that "employees' participation in safetyrelated activities positively influences the safety performance of the organization." This hypothesis is therefore confirmed, thus corroborating the literature on the subject.

The last hypothesis (H5) states that "a high degree of development of the safety management system has a positive impact on safety performance." According to Mitchison and Papadakis (1999), the safety management system is recognized in the literature as playing an essential role in achieving and maintaining good safety performance. However, contrary to expectations, the results obtained in the present study do not allow us to confirm this relationship. In view of this result, at least three questions that are deemed essential remain open: a) the safety management system, by itself, is not sufficient to have a positive impact on safety performance, with the influence of other variables (e.g. managers' commitment and employees' involvement) being necessary; $b$ ) this result is due to a measurement problem since, as mentioned above, the adjustment indices of the SMS measurement component do not reach the cutoff points considered acceptable; and c) 
notwithstanding the fact that this model already presents some evidence that may indicate some consistency in terms of the inherent dimensions of the safety culture concept, some key variables or dependencies may still remain to be identified.

\section{Limitations}

In the course of this study, some limitations emerged which should be taken into account, not only in the interpretation of the results but also for future studies. According to Silva, Lima, and Batista (2004), most empirical studies in the field of safety limit their sample to a very specific sector or organization, thus some doubts emerge regarding external validity. Although the present study endeavored to circumvent this limitation, as the sample consisted of participants from various organizations and sectors of activity, it is still not representative of the universe. On the other hand, based on the recommendations of Barrett (2007) and Kline (2016) regarding the minimum number of participants, wherein both suggested a sample of about 200 participants, the results of the present study should be interpreted with caution. Another limitation involves the fact that the instrument used is a self-reported one, whose bias possibilities are widely known. In addition, the fact that the participants are managers makes it necessary to take into account the "social desirability" factor with regard to the results inherent in the latent variable managers" commitment. It is also important to once again mention the problems associated with the SMS measure.

\section{Conclusion and future lines of investigation}

In conclusion, the present study aimed to test the model of Fernández-Muñiz et al. (2007) in the Portuguese context using a different target audience, also contributing to the adaptation of the measurement instrument that allowed its empirical testing. Despite the modest values of the goodness-of-fit indices of the theoretical model to the empirical data, the results obtained allowed us to draw some conclusions and present some theoretical and empirical contributions to the subject of safety culture, namely regarding the central role of managers. In fact, one of the most important practical implications that can be drawn from the results is that any intervention in safety issues should not neglect the role of managers, but rather the opposite. Given their role in influencing all other aspects of the system, interventions should be relevant to managers of organizations. Thus, such interventions will not only have a direct impact on managers, but will also affect the Safety Management System and employees' involvement.

In the future, it is essential for more empirical studies to be conducted, especially with different samples and in different contexts, so that the common dimensions between them can be identified, such as testing the Fernández-Muñiz et al. (2007) model in light of the perceptions of workers, as these may be considered as a valuable source of information. In addition, it is necessary to refine the SMS dimension measurement as it still has some weaknesses. This is essential for achieving a better fit of the model, and consequently a better understanding of the phenomenon. Regardless of the importance of such efforts, organizational culture, whether related to safety or not, is still something that is subjective and subject to differences depending on the environment, thus making this process hard to grasp.

\section{References}

Barrett, P. (2007). Structural equation modelling: Adjudging model fit. Personality and Individual Differences, 42(5), 815-924. doi:10.1016/j. paid.2006.09.018

Choudhry, R., Fang, D., \& Mohamed, S. (2007). The nature of safety culture: A survey of the state-of-the-art. Safety Science, 45(10), 993-1012. doi:10.1016/j.ssci.2006.09.003 
Cooper, D. (2000). Towards a model of safety culture. Safety Science, 36(2), 111-136. doi:10.1016/S0925-7535(00)00035-7

Cooper, D. (2001). Improving safety culture: A pratical guide. Hull: Applied Behavioural Sciences.

Cox, S., \& Cheyne, A. (2000). Assessing safety culture in offshore environments. Safety Science, 34(1-3), 111-129. doi:10.1016/S09257535(00)00009-6

Cox, S., \& Flin, R. (1998). Safety culture: Philosopher's stone or man of straw? Work \& Stress, 12(3), 189-201. doi:10.1080/02678379808256861

Donald, I., \& Young, S. (1996). Managing safety: An attitudinal-based approach to improving safety in organizations. Leadership \& Organization Development Journal, 17(4), 13-20. doi:10.1108/01437739610120556

Fernández-Muñiz, B., Montes-Peón, J., \& Vázquez-Ordás, C. (2007). Safety culture: Analysis of the causal relationships between its key dimensions. Journal of Safety Research, 38(6), 627-641. doi:10.1016/j.jsr.2007.09.001

Field, A. (2009). Discovering statistics using SPSS ( $3^{\text {rd }}$ ed.). London: SAGE Publications.

Frazier, C., Ludwig, T., Whitaker, B., \& Roberts, D. (2013). A hierarchical factor analysis of a safety culture survey. Journal of Safety Research, 45, 1528. doi:10.1016/j.jsr.2012.10.015

Glendon, A., \& Litherland, D. (2001). Safety climate factors, group differences and safety behaviour in road construction. Safety Science, 39(3), 157-188. doi:10.1016/S09257535(01)00006-6

Guldenmund, F. (2000). The nature of safety culture: A review of theory and research. Safety Science, 34(1-3), 215-257. doi:10.1016/S09257535(00)00014-X
Hale, A., Heming, B., Carthey, J., \& Kirwan, B. (1997). Modelling of safety management systems. Safety Science, 26(1-2), 121-140. doi:10.1016/ S0925-7535(97)00034-9

Halligan, M., \& Zecevic, A. (2011). Safety culture in healthcare: A review of concepts, dimensions, measures and progress. $B M J$ Quality \& Safety, 20(4), 334-343. doi:10.1136/ bmjqs.2010.040964

Hofmann, D., Jacobs, R., \& Landy, F. (1995). High reliability process industries: Individual, micro, and macro organizational influences on safety performance. Journal of Safety Research, 26(3), 131-149. Journal of Safety Research, 26(3), 131-149. doi:10.1016/0022-4375(95)00011-E

Hofmann, D., \& Stetzer, A. (1996). A crosslevel investigation of factors influencing unsafe behaviors and accidents. Personnel Psychology, 49(2), 307-339. doi:10.1111/j.1744-6570.1996. tb01802.x

Hopkins, A. (2006). Studying organisational cultures and their effects on safety. Safety Science, 44(10), 875-889. doi:10.1016/j.ssci.2006.05.005

International Safety Advisory Group (1991). Safety culture: A report by the International Nuclear Safety Group. Safety Series, 75(INSAG-4). Retrieved from: https://www-pub.iaea.org/ MTCD/Publications/PDF/Pub882_web.pdf

International Safety Advisory Group (1992). The Chernobyl accident: Updating of INSAG-1. Safety Series, 75(INSAG-7). Retrieved from: https://www-pub.iaea.org/MTCD/publications/ PDF/Pub913e_web.pdf

Kline, R. (2016). Principles and practice of structural equation modeling ( $4^{\text {th }}$ ed.). New York: The Guilford Press.

Koufteros, X. (1999). Testing a model of pull production: A paradigm for manufacturing research using structural equation modelling. 
Journal of Operations Management, 17(4), 467288. doi:10.1016/S0272-6963(99)00002-9

Locke, E. A., \& Latham, G. P., (1990). A theory of goal setting and task performance. New Jersey: Prentice-Hall, Englewood Cliffs.

Little, R., \& Rubin, D. (1989). The analysis of social science data with missing values. Sociological Methods and Research, 18(2-3), 292326. doi:10.1177/0049124189018002004

Maroco, J. (2010). Análise de equaçóes estruturais: Fundamentos teóricos, software \& aplicaçóes [Structural equation modeling: Theoretical foundations, software \& applications]. Pero Pinheiro: Reportnumber.

Michael, J., Evans, D., Jansen, K., \& Haight, J. (2005). Management commitment to safety as organizational support: Relationships with non-safety outcomes in wood manufacturing employees. Journal of Safety Research, 36(2), 171179. doi:10.1016/j.jsr.2005.03.002

Mitchison, N., \& Papadakis, G. (1999). Safety management systems under seveso II: Implementation and assessment. Journal of Loss Prevention in the Process Industries, 12(1), 43-51. doi:10.1016/S0950-4230(98)00036-9

Ostrom, L., Wilhelmsen, C., \& Daplan, B. (1993). Assessing safety culture. Nuclear Safety, 34(2), 163-172. Retrieved from: http://large. stanford.edu/courses/2015/ph241/davis-n1/docs/ assessingsafetyculture.pdf

Pestana, M., \& Gageiro, J. (2005). Análise de dados para ciências sociais: A complementariedade do SPSS [Data analysis for social sciences: The complementarity of SPSS] ( $4^{\text {th }} \mathrm{ed}$.). Lisboa: Ediçôes Sílabo.

Petersen, D. (2000). Safety management 2000: Our strengths \& weaknesses. Professional Development, 45(1), 16-19.
Porkka, P. (2016). Functional model for organisational and safety culture. Chemical Engineering Transactions, 48, 907-912. doi:10.3303/CET1648152

Reader, T., Noort, M., Shorrock, S., \& Kirwan, B. (2015). Safety sans fróntières: An international safety culture model. Risk Analysis, 35(5), 770789. doi:10.1111/risa.12327

Reicher, A., \& Schneider, B. (1990). Climate and culture: An evolution of constructs. In B. Schneider (ed.), Organizational climate and culture (pp. 5-39). San Francisco: Jossey-Bass.

Reiman, T., \& Rollenhagen, C. (2014). Does the concept of safety culture help or hinder systems thinking in safety?. Accident Analysis and Prevention, 68, 5-15. doi:10.1016/j. aap.2013.10.033

Richter, A., \& Koch, C. (2004). Integration, differentiation and ambiguity in safety cultures. Safety Science, 42(8), 703-722. doi:10.1016/j. ssci.2003.12.003

Schaffer, J. (1997). Analysis of incomplete multivariate data. Florida: CRC Press LLC.

Schneider, B., \& Gunnarson, S. (1991). Organizational climate and culture: The psychology of the workplace. In J. John, B. Steffy, \& D. Bray (Eds.), Applying psychology in business: The handbook for managers and human resource professionals (pp. 490-507). Maryland: Lexington Books.

Seo, D., Torabi, M., Blair, E., \& Ellis, N. (2004). A cross-validation of safety climate scale using confirmatory factor analytic approach. Journal of Safety Research, 35(4), 427-445. doi:10.1016/j. jsr.2004.04.006

Silva, S., Lima, M. L., \& Batista, C. (2004). OSCI: An organizational and safety climate inventory. Safety Science, 42(3), 205-220. doi:10.1016/S0925-7535(03)00043-2 
Stanton, N., Salmon, P., Jenkins, D., \& Walker, G. (2009). Human factors in the design and evaluation of central control room operations. Florida: CRC Press.

Watcher, J., \& Yorio, P. (2014). A system of safety management practices and worker engagement for reducing and preventing accidents: An empirical and theoretical investigation. Accident Analysis \& Prevention, 68, 117-130. doi:10.1016/j. aap.2013.07.029

Wiegmann, D. A., Zhang, H., Thaden, T. von, Sharma, G., \& Mitchell, A. (2002). A synthesis of safety culture and safety climate research. Illinois: University of Illinois. 


\section{Appendix A - Dimensions evaluated in Sample Characterization Questionnaire}

-Gender

-Age

-Educational level

-Sector where you work

-Size of the organization

-Specify the type of leadership you carry out in the organization

-How long have you held (in months) leadership roles in the current organization?

\section{Appendix B - Dimensions evaluated in Questionnaire regarding the variables of the conceptual model}

\begin{tabular}{|c|c|}
\hline \multicolumn{2}{|r|}{ Safety policy } \\
\hline Pol1 & Firm coordinates its health and safety policies with other HR policies to ensure commitment and well-being of workers. \\
\hline Pol2 & $\begin{array}{l}\text { A written declaration is available to all workers reflecting management's concern for safety, principles of action, and } \\
\text { objectives to achieve. }\end{array}$ \\
\hline Pol3 & $\begin{array}{l}\text { Management has established in writing the functions of commitment and participation and the responsibilities in safety } \\
\text { questions of all organizational members. }\end{array}$ \\
\hline Pol4 & Safety policy contains commitment to continuous improvement, attempting to improve objectives already achieved. \\
\hline \multicolumn{2}{|r|}{ Incentives for workers } \\
\hline Incent1 & $\begin{array}{l}\text { Incentives are frequently offered to workers to put in practice principles and action procedures (e.g. correct use of } \\
\text { protective equipment). }\end{array}$ \\
\hline Incent2 & Modifications to production processes or jobs consulted directly with workers affected or their representatives. \\
\hline Incent3 & Resolutions are frequently adopted that originate from consultations with or suggestions from workers. \\
\hline Incent4 & Meetings are periodically held between managers and workers to make decisions affecting organization of work. \\
\hline Incent5 & $\begin{array}{l}\text { Frequent use of teams made up of workers from different parts of organization to resolve specific problems relating to } \\
\text { working conditions. }\end{array}$ \\
\hline \multicolumn{2}{|r|}{ Training } \\
\hline Train1 & Workers are given a sufficient training period when joining firm, changing jobs, or using new techniques. \\
\hline Train2 & There is follow-up of training needs and efficacy or repercussions of training previously given. \\
\hline Train3 & Training actions are continuous and periodic, and are integrated into a formally established training plan. \\
\hline Train4 & Training plans are elaborated taking into account firm's particular characteristics. \\
\hline Train5 & Specific training plans are elaborated according to section or job position. \\
\hline Train6 & Training plans are decided jointly with workers or their representatives. \\
\hline Train7 & Training actions are carried out during working day. \\
\hline Train8 & Firm helps workers to train in-house (leave, grants). \\
\hline Train9 & Instruction manuals or work procedures are elaborated to aid in preventive action. \\
\hline
\end{tabular}




\section{Communication in prevention matters}

Commun1 There is fluent communication embodied in periodic and frequent meetings, campaigns, or oral presentations to transmit principles and rules of action.

Commun2 Information systems are made available to affected workers prior to modifications and changes in production processes, job positions, or expected investments.

Commun3 When starting a new job position, the worker is provided with written information about procedures and correct way of doing tasks.

Commun4 Written circulars are elaborated and meetings organized to inform workers about risks associated with their work and how to prevent accidents.

\begin{tabular}{|c|c|}
\hline \multicolumn{2}{|r|}{ Preventive planning } \\
\hline Prevent1 & Firm has systems to identify risks in all job positions. \\
\hline Prevent2 & Systems are in place to evaluate risks detected in all job positions. \\
\hline Prevent3 & $\begin{array}{l}\text { Prevention plans are formulated setting out measures to take based on information provided by risk evaluations in all } \\
\text { job positions. }\end{array}$ \\
\hline Prevent4 & Prevention plans clearly specify the person responsible for carrying out each action. \\
\hline Prevent5 & Standards of action or work procedures are elaborated based on risk evaluations. \\
\hline Prevent6 & Prevention plans are circulated among all workers. \\
\hline Prevent7 & Prevention plans are periodically reviewed and updated when job conditions are modified or workers' health is damaged. \\
\hline \multicolumn{2}{|r|}{ Emergency planning } \\
\hline Emerg1 & Firm has elaborated emergency plan for serious risks or catastrophes. \\
\hline Emerg2 & Firm has implemented its emergency plan. \\
\hline Emerg3 & All workers are informed of emergency plan. \\
\hline Emerg4 & Periodic simulations are carried out to check efficacy of emergency plan. \\
\hline
\end{tabular}

\begin{tabular}{|c|c|}
\hline \multicolumn{2}{|r|}{ Internal controls } \\
\hline Intern1 & Periodic checks are conducted regarding execution of prevention plans and level of compliance with regulations. \\
\hline Intern2 & $\begin{array}{l}\text { Standards or pre-determined plans and actions are compared, evaluating implementation and efficacy in order to } \\
\text { identify corrective action. }\end{array}$ \\
\hline Intern3 & Procedures are in place (reports, periodic statistics) to check achievement of objectives allocated to managers. \\
\hline Intern4 & Systematic inspections are conducted periodically to ensure effective functioning of whole system. \\
\hline Intern 5 & Accidents and incidents are reported, investigated, analyzed, and recorded. \\
\hline
\end{tabular}

\section{Benchmarking techniques}

Bench1 Firm's accident rates are regularly compared with those of other organizations from same sector using similar production processes.

Bench2 Firm's techniques and management practices are regularly compared with those of other organizations from all sectors in order to obtain new ideas about management of similar problems.

\section{Managers' attitudes}

Attitud1 Managers consider that employees' participation, commitment, and involvement are fundamental to health and safety activities in order to reduce the work accident rate.

Attitud2 Managers consider that training of employees is essential for achieving a safe workplace.

Attitud3 Managers consider that internal communication is essential to understand and implement safety policy.

Attitud4 Managers consider that it is fundamental to monitor activities in order to maintain and improve safety activities. 


\section{Managers' behavior}

Behav1 Firm managers take responsibility for health and safety as well as quality and productivity.

Behav2 Managers actively and visibly lead in safety matters.

Behav3 Safety is a work requirement and a condition of contracting.

Behav4 Managers regularly visit workplace to check work conditions or to communicate with employees.

Behav5 Managers encourage meetings with employees and directors to discuss safety matters.

\section{Employees' involvement}

Involv1 Employees are involved in creating guidelines for procedures and instruction manuals.

Involv2 Employees participate actively in devising, executing, and monitoring safety plans.

Involv3 Employees comply with safety regulations.

Involv4 Employees provide written suggestions in event of any deficiencies in working conditions.

\section{Safety performance}

\begin{tabular}{ll}
\hline Safety1 & Personal injuries \\
Safety2 & Material damage \\
Safety3 & Employees' motivation \\
Safety4 & Absenteeism/Lost time \\
\hline
\end{tabular}




\section{Authors:}

1. André Job, Master in Applied Psychology, University of Minho, Braga, Portugal.

E-mail: andrenunesjob@gmail.com

\section{ORCID}

iD 0000-0001-6648-8502

2. Isabel Silva, Doctor in Work and Organizational Psychology, University of Minho, School of Psychology, Braga, Portugal.

E-mail: isilva@psi.uminho.pt

\section{ORCID}

iD 0000-0002-2931-7218

3. Tânia Moreira, Master in Applied Psychology, University of Minho, School of Psychology Braga, Portugal.

E-mail: taniatmoreira@gmail.com

\section{ORCID}

iD 0000-0002-8113-1795

\section{Contribution of each author}

\begin{tabular}{|c|c|c|c|}
\hline Contribution & André Job & Isabel Silva & Tânia Moreira \\
\hline 1. Definition of research problem & $\sqrt{ }$ & $\sqrt{ }$ & \\
\hline 2. Development of hypotheses or research questions ( empirical studies ) & $\sqrt{ }$ & $\sqrt{ }$ & \\
\hline \multicolumn{4}{|l|}{ 3. Development of theoretical propositions ( theoretical Work ) } \\
\hline 4. Theoretical foundation/ Literature review & $\sqrt{ }$ & $\sqrt{ }$ & \\
\hline 5. Definition of methodological procedures & $\sqrt{ }$ & $\sqrt{ }$ & \\
\hline 6. Data collection & $\sqrt{ }$ & & \\
\hline 7. Statistical analysis & $\sqrt{ }$ & $\sqrt{ }$ & $\sqrt{ }$ \\
\hline 8. Analysis and interpretation of data & $\sqrt{ }$ & $\sqrt{ }$ & $\sqrt{ }$ \\
\hline 9. Critical revision of the manuscript & & $\sqrt{ }$ & $\sqrt{ }$ \\
\hline 10. Manuscript Writing & $\sqrt{ }$ & $\sqrt{ }$ & \\
\hline 11. Other (please specify which) & & & \\
\hline
\end{tabular}

